\title{
THE RELATIONSHIP OF MOVEMENT SKILLS WITH HABITUAL AND ORGANIZED PHYSICAL ACTIVITY IN SEVEN AND EIGHT-YEAR- OLD CHILDREN ${ }^{1}$
}

\author{
Oldemar Mazzardo \\ Universidade Estadual do Oeste do Paraná, Cascavel, Paraná, Brasil \\ Fábio Eduardo Fontana \\ University of Northern Iowa, Cedar Falls, Iowa, Estados Unidos da América \\ Ovande Furtado \\ California State University, Northridge, Califórnia, Estados Unidos da América \\ Jere D. Gallagher \\ University of Pittsburgh, Pittsburgh, Pennsylvania, Estados Unidos da América
}

\begin{abstract}
Summary
PURPOSE: To verify the association of motor skills with habitual and organized PA participation, and sedentary behavior for males and females. METHODS: The study employed a cross-sectional design in a sample of seventy-six second graders from a public elementary school in a Midwestern State. RESULTS: Mann Whitney and t-tests indicated gender differences in FMS and PA variables. Spearman correlation analyses demonstrated that habitual PA was correlated to total FMS, and manipulative skills for boys. For girls, a significant association was present in organized PA and locomotor skills. CONCLUSION: Choice of organized physical activity seems to influence the development of FMS and affect habitual PA behavior differently in boys and girls.
\end{abstract}

Keywords: Motor skills. Child development. Motor activity.

\section{Introduction}

The decline in physical activity (PA) among adolescents (NG; POPKIN, 2012) has prompted interest in understanding the underlying mechanisms that influence children's PA with the assumption that behaviors acquired in early childhood are generally maintained in late childhood and adolescence (VAN DER HORST et al., 2007). A potentially important PA determinant in young children with adolescent's PA participation and physical fitness is fundamental movement skill (FMS) (CLIFF et al., 2009; LLOYD et al., 2014; STODDEN; LANGENDORFER; ROBERTO, 2009). In fact, low competency in FMS is strongly associated with lower cardiorespiratory fitness and PA levels in children and adolescents (HARDY et al., 2012; LUBANS et al., 2010).

\footnotetext{
${ }^{1} \mathrm{O}$ presente trabalho não contou com apoio financeiro de nenhuma natureza para sua realização.
} 
A systematic review of the relationship between FMS and PA (LUBANS et al., 2010) indicated an overall positive association between FMS and PA level among children and adolescents. However, the same study also reported some investigations with non-significant findings. These conflicting results encouraged Stodden and colleagues (2008) to present a developmental model explaining the influence of correlates of PA for prepubescent children and adolescents.

The model suggests that the relationship between FMS competence and PA will strengthen as the child progresses from early to late childhood. Physical activity behavior during early childhood (up to 5 years) seems to be dependent more on the opportunities to be active than on the choices of participation (STERDT; LIERSCH; WALTER, 2013). As children mature, they increase their capacity of self-assessing their motor skill competence, having a more accurate understanding of their motor abilities in comparison to their peers (BARNETT et al., 2010). In fact, the relationship of FMS and PA in eight-year-old children is mediated by perception of competence (KHODAVERDI et al., 2016). At this point of development, children with poor developed motor skills may halt their participation in games and sport activities avoiding to expose their low level of motor skill competence. As the child moves from early to middle to late childhood (middle school aged), the importance of the FMS level increases and the association of FMS with PA participation become more evident favoring those with higher FMS (HUME et al., 2008; WROTNIAK et al., 2006). There is a consensus in the motor development literature (GALLAHUE; CLELAND, 2007) that a welldeveloped repertoire of motor skills facilitates participation in sport and recreational physical activities. A question that remains to be answered is whether FMS have a similar effect on physical activity participation in early school years.

In addition, the recent use of more comprehensive FMS tests, such as the TGMD-II (ULRICH, 2000), made possible the assessment of specific components of motor skills raising the question whether the widely assumed relationship between FMS and habitual PA is generalized to the entire set of skills or skill specific. The TGMD-II merges skills into the categories of locomotor and object control. Several studies in the last seven years have found that competence in FMS is related to PA level only for locomotor (WILLIAMS et al., 2008) and object controls skills (CLIFF et al., 2009; MORGAN et al., 2008; WROTNIAK et al., 2006).

The purpose of this study was to examine the relationship between FMS and PA level in second graders. We wanted to assess second graders because they have had already one year of experience developing and refining motor skills during physical education classes and after school programs. We hypothesized that for seven and eight-year-old children a relationship between mastery of FMS and PA would exist. Comprehensive information about the type of activities in which children participate may help educators to understand the skill specific relationships between FMS and PA behavior. Therefore, two complimentary measures of PA (habitual and organized) with a process-oriented FMS test were used in the study. The association between sedentary behavior and FMS was also investigated.

\section{Material and Methods}

The study employed a cross-sectional design to investigate the relationship between children's FMS and PA. We evaluated participants on two measures of PA and one test of motor skills. The variables were total FMS, manipulative skills, locomotor skills, habitual PA (average step count), and organized PA. 


\section{Participants}

The sample of 76 children, selected by convenience from a population of 183 secondgrade students from a public elementary school in the Midwest, included 42 males and 34 females, mean age 7.8 years $(\mathrm{SD}=.6)$ for males, and 7.8 years $(\mathrm{SD}=.3)$ for females. All second graders received the opportunity to participate; however, only data from children who were healthy and free from diagnosed orthopedic, neurologic, physical impairments or developmental conditions were included in the data analysis. Prior to participation in the study, written informed consent was obtained from parents.

\section{Instruments and Procedures}

The involvement of a child in the research study depended on active collaboration of one or both parents who assisted the child with pedometer placement and use, recorded daily steps, and completed a proxy-questionnaire about their child's participation in organized PA. The parents were contacted via a letter sent by the school's Principal explaining the objectives of the investigation and encouraging their participation. Parents or legal guardians signed the informed consent prior to the inclusion of the child in the study. Eligible participants received a packet containing a pedometer, a diary booklet, a proxy-questionnaire, and directions about research procedures. Both, the diary booklet and the proxy-questionnaire were selfexplanatory.

\section{Anthropometric measures}

Height and weight measurements were recorded prior to the performance of the skill test. Total height was assessed with a Seca portable stadiometer to the nearest $0.1 \mathrm{~cm}$, and the body mass to within $0.1 \mathrm{~kg}$ on a Tanita digital scale. BMI scores were calculated for sample descriptive purposes only.

\section{Habitual Physical Activity}

For the habitual PA data, we used the Yamax Digi-Walker SW-200 pedometer, which is an accurate and reliable step counter (SCHNEIDER; CROUTER; BASSETT, 2004; SIRARD; PATE, 2001). Children wore the pedometers for six consecutive days, including four weekdays and two weekend days, meeting recommendations for measuring PA habits (CORDER et al., 2008). Parents positioned the pedometer on the child's belt or waistband above the thigh midline section of the dominant side. The participants wore the pedometers throughout the day, from waking until going to bed, except during bathing, water activities or sleeping.

Parents maintained a record of the daily number of steps and of the time the pedometer was attached to the child's waist from morning to night. In the diary, parents responded to whether the day recorded was a typical day in their child's life. The exclusion criteria for atypical days included the following situations: travelling, illness, and missing school days for other reasons. Only subjects who reported useful data on at least three weekdays and one weekend day were included in the analysis.

The outcome variable taken from the diary booklet was the average step count per hour per week. Calculating this variable required averaging the number of hours for the number of weekdays and weekend days. 


\section{Organized Physical Activity}

Since the utilization of self-report questionnaires is not recommended for children younger than 10 years (SIRARD; PATE, 2001), a proxy questionnaire was used for recalling participation in organized physical activities. The proxy-questionnaire was adapted from the Past Year Physical Activity Questionnaire (AARON et al., 1995).

Organized PA referred to activities (competitive/recreational/educational) that had a scheduled meeting time (weekly or monthly) and were led by an instructor, teacher or coach. Respondents indicated each of the organized PA in which their child had been involved in the past year, as well as the frequency and duration of participation. They reported the frequency of participation as days per week and number of months during the past year, and the duration as the number of hours or fraction of an hour per day. The questionnaire yielded an estimate of the average number of minutes per week spent in each activity during the previous year. The average minutes from all activities add up to derive an overall average weekly-organized physical activity.

\section{Sedentary Activity}

Parents also responded to questions that assessed their child's average participation in sedentary activities during weekdays and weekend days. The activities listed in the questionnaire were watching TV, playing video or computer games, surfing the internet or using the computer, doing school-homework, and reading. Blank spaces were provided to allow recording of activities not listed. The measures were frequency and duration. The outcome variable was the estimated weekly sedentary activity in minutes.

Finally, the proxy questionnaire asked parents about their child's health during the past year. More specifically, they were asked about any health issue that incapacitated or prevented the child from participating in physical activity for more than 30 days. The estimated time to complete the proxy questionnaire was approximately 20 minutes.

\section{Fundamental motor skills test}

The motor skills test performed by the subjects was the Test of Gross Motor Development (TGMD-II), a process oriented motor test (ULRICH, 2000). The data collection followed standardized test procedures as provided in the test manual. Arrangements were made to accommodate the test in a safe environment and to minimize administration time and distractions. Two examiners and two cameramen led each session reading descriptions and providing accurate demonstrations of each skill. The TGMD-II test consists of 12 skills, six locomotor and six object control skills. Each child completed two independent trials of each skill with no feedback between or after the trials. The average time for completion of the test was about 20 to 25 minutes.

Once testing was completed, video analysis of the motor skills was conducted by two raters, with an inter-rater reliability of .91. Each motor skill was broken into a set of three to five performance criteria which represented pieces of advanced patterns of the motor skills, following the TGMD2 test guidelines. Both the locomotor and object control skill subtests had a maximum score of 48 and a minimum of zero. Results for locomotor, object control, and total motor skills were calculated by totaling the correctly performed criteria. 


\section{Data Analyses}

Descriptive statistics of age (Mean and SD) and BMI was computed for both males and females. Data from all variables were examined for normality using the ShapiroWilk statistical test. Based on the test for normality, parametric and non-parametric analyzes were performed. Independent t-tests were used to examine sex differences in the Habitual PA (step count) and the FMS variables, while Mann-Whitney tests examined gender differences in the non-parametric variables. Since sex differences were present for some of the variables, Spearman Rho correlations were computed separately for males and females to examine the association among PA variables (step count, organized PA) and sedentary activities, with the FMS variables (total FMS, locomotor, and object control skills). All statistical procedures were performed using the SPSS 17.0 statistical package.

\section{Results}

Seventy-six children were initially included in the study; however, twenty-eight children were disqualified from the final pool of subjects. The reasons for exclusions is described as follows: Eighteen children and/or parents were not compliant with the study requirements and failed to complete and return the diary, the questionnaire, or both; Three subjects dropped out of the study a few days after starting data collection; Five children completed the requirements but did not have four days of step count data; Two children participated in all stages but were excluded from the analysis for having a disability. The final sample of participants consisted of forty-eight children ( 27 males, 21 females). Both groups were similar in age (males $\mathrm{M}=7.6, \mathrm{SD}=.3$, females $\mathrm{M}=7.8, \mathrm{SD}=.4$ ) and race (males $90.5 \%$ Caucasian, females 85.2\% Caucasian).

Gender was a factor in the performance of FMS and in habitual PA. Significant gender differences were found for total FMS and object control skills. Independent $t$-tests demonstrated that males outperformed females in the total FMS and manipulative skills. The same pattern of results with males outperforming females was present in habitual PA. See other results for gender differences on table 1 .

Table 1.Gender Differences in FMS, PA, Sedentary Activity and BMI

\begin{tabular}{|c|c|c|c|c|c|}
\hline & Male $(n=27)$ & Female $(\mathrm{n}=21)$ & T-test & $\begin{array}{c}\text { Mann-Whitney } \\
\text { U test }\end{array}$ & p-value \\
\hline BMI & $\mathrm{Md}=16.1(13.9 / 16.7)$ & $\mathrm{Md}=16.4(12.5 / 26.2)$ & ------ & 270 & 0.78 \\
\hline Total FMS & $\bar{x}=62.6(7.7)$ & $\overline{\mathrm{x}}=57.4$ & 2.729 & ------ & 0.01 \\
\hline Locomotor skills & $\overline{\mathrm{x}}=30.9(3.6)$ & $\bar{x}=29.2$ & 1.522 & ------ & 0.14 \\
\hline Object control skills & $\overline{\mathrm{x}}=31.8(5.8)$ & $\overline{\mathrm{X}}=28.1$ & 2.586 & ------ & 0.01 \\
\hline Habitual PA & $\overline{\mathrm{x}}=1104(340)$ & $\overline{\mathrm{x}}=882(254)$ & 2.498 & ------ & 0.02 \\
\hline Organized PA & $\mathrm{Md}=75(0 / 520)$ & $\mathrm{Md}=160(0 / 590)$ & ------ & 198 & 0.08 \\
\hline Sedentary Activity & $M d=1035(285 / 2155)$ & $\mathrm{Md}=1215(540 / 2870)$ & ------ & 224 & 0.22 \\
\hline
\end{tabular}

Note. $\overline{\mathrm{x}}=$ Mean (Standard Deviation); Md = Median (min/max)

The results of Spearman correlations among the PA (habitual PA, organized PA and sedentary activity) and the motor skills variables (total FMS scores, object control and locomotor) are depicted in Table 2. For males, there were significant moderate associations be- 
tween step count and total FMS, and object control skills. No associations were found for the habitual PA and locomotor skills. The same trend of results was detected for the association between organized PA and motor skill variables. Participation in organized PA was also moderately associated with total FMS and object control skills but not for locomotor skills. Analysis of the associations of variables demonstrated fewer significant results for females. Participation in organized PA was moderately and significantly associated with total FMS and locomotor skills.

Table 2. Spearman Rank Order Correlation Coefficients for FMS and PA variables

\begin{tabular}{ccccc}
\hline \multirow{2}{*}{ Gender } & Total FMS & Manipulative & Locomotor \\
\cline { 3 - 5 } & & $\mathrm{R}$ & $\mathrm{r}$ & $\mathrm{R}$ \\
\hline \multirow{2}{*}{ Habitual PA } & Male & $.39^{*}$ & $.46^{* *}$ & .12 \\
& Female & .26 & .35 & .21 \\
\hline \multirow{2}{*}{ Organized PA } & Male & $.38^{*}$ & $.35^{*}$ & .31 \\
& Female & $.41^{*}$ & -.11 & $.56^{* *}$ \\
\hline \multirow{2}{*}{ Sedentary Activity } & Male & -.06 & .03 & -.14 \\
& Female & -.01 & -.19 & .16 \\
\hline
\end{tabular}

Note. $*$ Significant at $\mathrm{p} \leq 05 ; * *$ Significant at $\mathrm{p} \leq .01$

Habitual PA measured by step count did not correlate to the time spent in organized PA for males $(\mathrm{r}=.12 ; \mathrm{p}=.55)$ or females $(\mathrm{r}=.07 ; \mathrm{p}=.77)$. Results suggest that free activities may be more important for seven and eight-year-old children to account for individual differences in overall physical activity levels.

The distribution of physical activities reported in the proxy questionnaire are described in Figure 1. The activities were separated by sex and grouped into 4 categories (manipulative, locomotor, aquatics or other). The manipulative category consisted of baseball, basketball, soccer, field hockey, tennis and softball. The locomotor activities were gymnastics, cheerleading, dance, ice skating and martial arts. Other activities were bowling, horseback riding, and non-specified recreational camps. Finally, the aquatics consisted of swimming and diving.

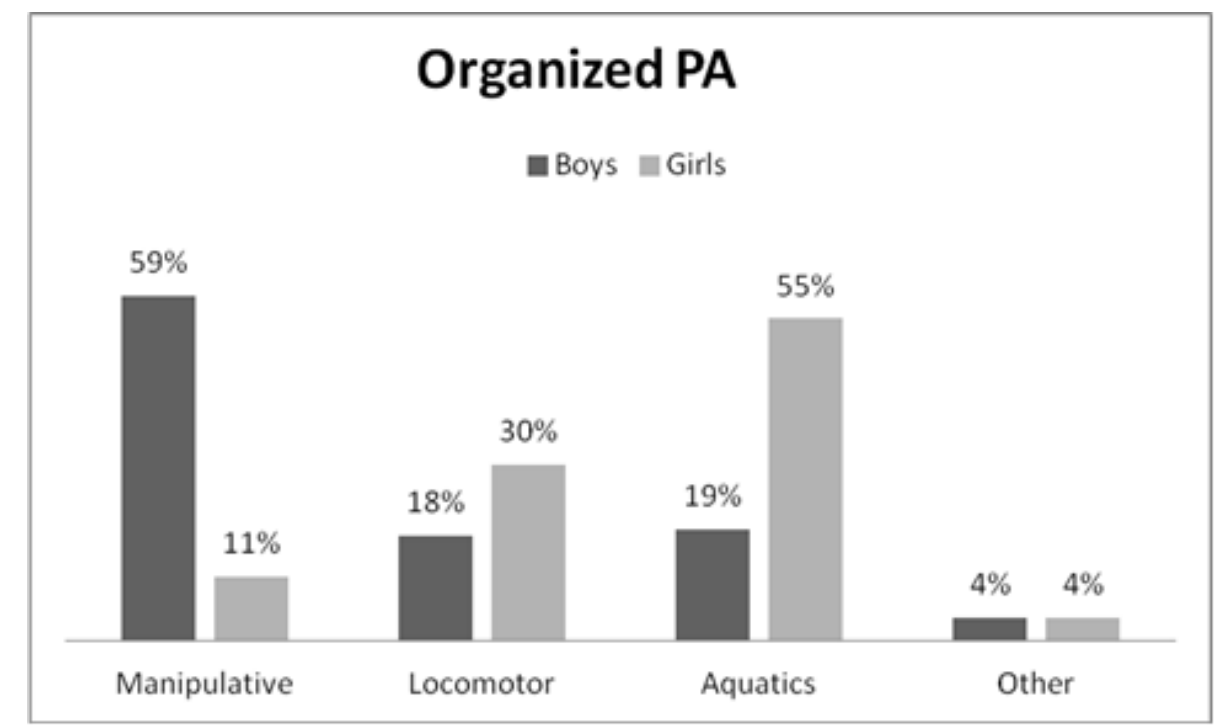

Figure 1. Percentage of Organized PA participation by gender

\section{Discussion}


The objective of this study was to examine the association between FMS proficiency and two measures of PA level (habitual and organized) in 7 and 8-year-old children. Results indicated that proficiency of FMS is significantly associated with PA, although the association is dependent upon gender and the type of motor skill.

Gender differences were present in motor skill proficiency. Males outperformed females in total FMS and manipulative skills, corroborating previous research with primary school children (GRAF et al., 2004; WROTNIAK et al., 2006) and adolescents (LUBANS et al., 2010). Gender may be a confounding factor accounting for some of the variability in the strength of the relationship between PA and motor skills. Studies of children's movement skills typically show no gender differences during early childhood; however, differences increase over time and are observed for middle school age children (HEITZLER et al., 2006).

Although biological disposition cannot be completely ruled out, gender differences in the motor skill level of pre-pubescent children may be mostly attributed to social and environmental factors. Gender role stereotyping where boys' participation in physical activity and sport is favored may be present early in life (GABBARD, 2012). In fact, males receive stronger support than females from parents and peers to begin and continue in sports (WRIGHT et al., 2010). These potential confounding social factors may influence not only the motor skill development but also the physical activity level of children.

Significant differences were also observed in habitual PA, with higher PA level for boys. This is in agreement with previous findings reporting gender as a consistent predictor of PA in children (JACKSON et al., 2003; PEARCE et al., 2012). The advantage of higher levels of participation in free-living physical activities is consistent from early childhood to adolescence. However, when PA was measured by structured activities, no gender differences were reported. The level of total participation in organized PA in the present study was similar between boys and girls, although choice of activities were gender specific.

The percentage of participation in at least one organized PA in the previous year was high for both males and females with $96.3 \%$ and $89.5 \%$ respectively. The groups were similar in the average minutes per week spent in organized PA during the previous year. Males tried out more activities than females (2.8 vs. 2.2 average activities per year), but females persisted longer than males in the chosen activities, respectively 2.6 vs 4.4 months of participation per activity.

The choices of activities differed in nature and seasonality. Males' choice of activities included as expected object control seasonal activities (e.g. basketball, baseball, football, soccer) while females chose to participate in locomotor based, year-round physical activities (e.g. gymnastics, swimming, cheerleading, dance). Whether the choice of activities represents availability of PA programs for males and females, parental or children's choice is unknown. Nevertheless, organized PA choices may help explain, to some extent, the specificity of the associations between FMS performance and habitual physical activity level.

There were significant correlations between FMS and habitual PA for males. That is, boys with a higher total FMS score had a higher weekly average step count per hour. We found slightly stronger correlations between habitual PA and total FMS ( $\mathrm{r}=.39)$ and manipulative skills $(\mathrm{r}=.46)$ in comparison to previous research findings reporting correlation coefficients between .18 and .35 (FISHER et al., 2005; REED; METZKER; PHILLIPS, 2004; WROTNIAK et al., 2006). An explanation may be the use of a more sensitive motor skill assessment instrument (STODDEN et al., 2008). The aforementioned studies have used product-oriented assessments to examine the relationship of physical activity to fundamental movement skills among children and adolescents. This study applied a process-oriented motor skill assessment, which increased the potential for accurately detecting qualitative aspects of fundamental motor skill performance. Our findings corroborate the results of Morgan et al. 
(2008), who demonstrated that object control skills predicted a significant amount of variance in the vigorous and total amount of PA in elementary school obese children. Morgan's study also used the TGMD 2 instrument for FMS assessment.

The correlation between FMS and habitual PA in males reflects higher proficiency of manipulative skills but not of locomotor skills. Typically, children demonstrate an earlier onset of acquisition and mastery of locomotor skills and only then acquire manipulative skills (GALLAHUE; CLELAND, 2007). It may be the case that seven and eight-year-old boys are more advanced in the acquisition of locomotor skills, near a mature pattern, demonstrating a more homogeneous performance level within the group, while a greater performance range (from immature to near mature patterns) is observed for manipulative skills (see SD in Table 1). Corroborating with previous research (HUME et al., 2008; MORGAN et al., 2008) it appears that the use of manipulative skills may be more appropriate to discriminate motor skill proficiency and its correlation to physical activity level for boys.

For females, no significant associations were observed for habitual PA and FMS. Organized PA was significantly associated to FMS in the total score and locomotor skills, however, no association was observed for manipulative skills. Female's manipulative skill proficiency and habitual PA levels were significantly lower than those of males. Wrotniak et al. (2006), suggested that there might be a threshold in motor skill development that results in higher physical activity levels for children. They observed that children in the highest quartile of motor proficiency were significantly more physically active than children in the lowest quartile of motor proficiency. Our findings partially support the notion of an existing threshold at which children may be most physically active; however, this threshold seems specific to the development of manipulative skills.

For females, the significant correlations between participation in organized PA and motor skills are in agreement with previous findings (OKELY; BOOTH; PATTERSON, 2001) which reported a statistically significant relationship between time spent in organized physical activity and locomotor skills in adolescent females. Collectively, results from these two studies suggest that this association may be long lasting. Increased locomotor skills in elementary school years may result in continued participation in organized PA and higher overall motor skill proficiency levels later in adolescence. In addition, the absence of a correlation between habitual PA and total FMS, locomotor, or manipulative skills suggests that opportunities for females to develop motor skills are more strongly dependent on participation in organized PA.

\section{Conclusions}

In agreement with the literature (OKELY; BOOTH; PATTERSON, 2001; PEARCE et al., 2012) the development of motor skill and physical activity participation, particularly organized PA, might be reciprocal determinants. That is, having high FMS level may increase options for participation in PA, as well as increased participation could lead to further development of motor skills.

Participation in structured activities during early childhood seems to influence the development of FMS and indirectly affect habitual PA behavior. Early in elementary school, children are still very similar in the level of skill development and may therefore select their participation in organized PA by levels of enjoyment, peer or parental influence (GABBARD, 2012). The present results reinforce how critical it is that adequate time and resources be devoted to skill development by participating in appropriate organized PA, especially during early elementary school years, when a window of opportunity exists to maximize the learning of new skills (GALLAHUE; CLELAND, 2007). 
The association between FMS and PA in second graders is gender and skill related. The difference in FMS development between gender may be related to the availability or choice of activities during middle childhood. Interventions designed to increase habitual PA levels in seven and eight-year-old children should incorporate the development of FMS, more intensively targeting manipulative skills for both males and females. Further research should investigate the threshold of motor skill development necessary for promoting higher levels of PA behavior.

This study is not without limitations. A larger sample size was desirable. The small number of subjects limited the power of statistical analyzes. However, the inclusion of two measures of PA and the use of a process oriented FMS test are strengths of the study that allowed for additional understanding of the skill specific associations between FMS and PA.

\section{ASSOCIAÇÃO ENTRE HABILIDADES MOTORAS E ATIVIDADE FÍSICA HABI- TUAL E ORGANIZADA EM CRIANÇAS DE SETE E OITO ANOS}

\section{Resumo}

OBJETIVO: Verificar as associações de Habilidades Motoras Fundamentais (HMF) com a participação em Atividade Física (AF) e comportamento sedentário em meninos e meninas. MÉTODO: O estudo utilizou um delineamento transversal em uma amostra de alunos de escola pública. RESULTADOS: Mann Whitney e testes-t indicaram diferenças de gênero na HMF e variáveis de AF e comportamento sedentário. As análises de correlação demonstraram que AF habitual esteve significativamente associada com HMF total e manipulação de objetos nos meninos. Para as meninas, associações significativas foram observadas entre AF organizada e habilidades locomotoras. CONCLUSÃO: A participação em AF organizada parece influenciar o desenvolvimento de habilidades motoras e o comportamento de AF habitual.

Palavras-chave: Destreza motora. Desenvolvimento infantil. Atividade física.

\section{ASOCIACIÓN ENTRE HABILIDADES MOTRICES Y ACTIVIDAD FÍSICA HABI- TUAL Y ORGANIZADA EN NIÑOS DE SIETE Y OCHO AÑOS}

\section{Resumen}

OBJETIVO: Verificar asociaciones entre las HABILIDADES MOTORAS FUNDAMENTALES (HMF) con la participación en Actividad Física (AF) y el comportamiento sedentario. MÉTODO: El estudio utilizó un diseño transversal en una muestra de estudiantes de escuela pública. RESULTADOS: Mann-Whitney y testes-t indicaron diferencias de género en variables de HMF, AF y el comportamiento sedentario. Los análisis de correlación demostraron que la AF habitual estuvo significativamente asociada con HMF total y manipulación de objetos en los niños. Para las niñas, asociaciones significativas fueron observadas entre AF organizada y habilidades locomotoras. CONCLUSIÓN: La participación en AF organizada parece influir en el desarrollo de las habilidades motoras y el comportamiento de la AF habitual.

Palabras clave: Destreza motora. Desarollo infantil. Actividad física.

\section{References}

AARON, D. J. et al. Reproducibility and validity of an epidemiologic questionnaire to assess past year physical activity in adolescents. American journal of epidemiology, v. 142, n. 2, p. 191-201, jul. 1995. 
BARNETT, L. M. et al. A Reverse Pathway? Actual and Perceived Skill Proficiency and Physical Activity. Medicine \& Science in Sports \& Exercise, v. 43, n. 5, p. 898-904, 2010.

CLIFF, D. P. et al. Relationships between fundamental movement skills and objectively measured physical activity in preschool children. Pediatric exercise science, v. 21, n. 4, p. 436-49, nov. 2009.

CORDER, K. et al. Assessment of physical activity in youth. Journal of applied physiology (Bethesda, Md. : 1985), v. 105, n. 3, p. 977-87, set. 2008.

FISHER, A. et al. Fundamental Movement Skills and Habitual Physical Activity in Young Children. Medicine \& Science in Sports \& Exercise, v. 37, n. 4, p. 684-688, abr. 2005.

GABBARD, C. P. Lifelong Motor Development. 6th. ed. [s.1.] Benjamin-Cummings Publishing Company, 2012.

GAllahue, D. L.; ClELAND, F. Developmental Physical Education for All Children. 5th. ed. Champaign, IL: Human Kinetics, 2007.

GRAF, C. et al. Correlation between BMI, leisure habits and motor abilities in childhood (CHILT-project). International journal of obesity and related metabolic disorders: journal of the International Association for the Study of Obesity, v. 28, n. 1, p. 22-6, jan. 2004.

HARDY, L. L. et al. Prevalence and correlates of low fundamental movement skill competency in children. Pediatrics, v. 130, n. 2, p. e390-8, ago. 2012.

HEITZLER, C. D. et al. Correlates of physical activity in a national sample of children aged 9-13 years. Preventive medicine, v. 42, n. 4, p. 254-60, abr. 2006.

HUME, C. et al. Does weight status influence associations between children's fundamental movement skills and physical activity? Research quarterly for exercise and sport, v. 79, n. 2, p. 158-65, jun. 2008.

JACKSON, D. M. et al. Objectively measured physical activity in a representative sample of 3- to 4-year-old children. Obesity research, v. 11, n. 3, p. 420-5, mar. 2003.

KHODAVERDI, Z. et al. The relationship between actual motor competence and physical activity in children: mediating roles of perceived motor competence and health-related physical fitness. Journal of Sports Sciences, v. 34, n. 16, p. 1523-1529, 17 ago. 2016.

LLOYD, M. et al. Long-term importance of fundamental motor skills: A 20-year follow-up study. Adapted Physical Activity Quarterly, v. 31, n. 1, p. 67-78, 2014.

LUBANS, D. R. et al. Fundamental movement skills in children and adolescents: Review of associated health benefits. Sports Medicine, v. 40, n. 12, p. 1019-1035, dez. 2010.

MORGAN, P. J. et al. Correlates of objectively measured physical activity in obese children. Obesity (Silver Spring, Md.), v. 16, n. 12, p. 2634-41, dez. 2008. 
NG, S. W.; POPKIN, B. M. Time use and physical activity: a shift away from movement across the globe. Obesity reviews : an official journal of the International Association for the Study of Obesity, v. 13, n. 8, p. 659-80, ago. 2012.

OKELY, A. D.; BOOTH, M. L.; PATTERSON, J. W. Relationship of physical activity to fundamental movement skills among adolescents. Medicine and science in sports and exercise, v. 33, n. 11, p. 1899-904, nov. 2001.

PEARCE, M. S. et al. Early predictors of objectively measured physical activity and sedentary behaviour in 8-10 year old children: the Gateshead Millennium Study. PloS one, v. 7, n. 6, p. e37975, jan. 2012.

REED, J. A.; METZKER, A.; PHILLIPS, D. A. Relationships between physical activity and motor skills in middle school children. Perceptual and motor skills, v. 99, n. 2, p. 483-94, out. 2004.

SCHNEIDER, P. L.; CROUTER, S. E.; BASSETT, D. R. Pedometer measures of free-living physical activity: comparison of 13 models. Medicine and science in sports and exercise, $\mathrm{v}$. 36, n. 2, p. 331-5, fev. 2004.

SIRARD, J. R.; PATE, R. R. Physical activity assessment in children and adolescents. Sports medicine (Auckland, N.Z.), v. 31, n. 6, p. 439-54, jan. 2001.

STERDT, E.; LIERSCH, S.; WALTER, U. Correlates of physical activity of children and adolescents: A systematic review of reviews. Health Education Journal, v. 73, n. 1, p. 7289, 13 jan. 2013.

STODDEN, D. F. et al. A Developmental Perspective on the Role of Motor Skill Competence in Physical Activity: An Emergent Relationship. Quest, v. 60, n. 2, p. 290-306, maio 2008.

STODDEN, D.; LANGENDORFER, S.; ROBERTO, M. A. The Association Between Motor Skills Competence and Physical Fitness in Young Adults. Research Quarterly for Exercise and Sport, v. 80, n. 2, p. 223-229, 2009.

ULRICH, D. The test of gross motor developmentAustinProd-Ed, , 2000.

VAN DER HORST, K. et al. A brief review on correlates of physical activity and sedentariness in youth. Medicine and science in sports and exercise, v. 39, n. 8, p. 1241-50, ago. 2007.

WILLIAMS, H. G. et al. Motor skill performance and physical activity in preschool children. Obesity (Silver Spring, Md.), v. 16, n. 6, p. 1421-6, jun. 2008.

WRIGHT, M. S. et al. A qualitative study of parental modeling and social support for physical activity in underserved adolescents. Health education research, v. 25, n. 2, p. 22432, abr. 2010.

WROTNIAK, B. H. et al. The relationship between motor proficiency and physical activity in children. Pediatrics, v. 118, n. 6, p. e1758-65, dez. 2006. 
Recebido em: 15/07/2016

Revisado em: 28/10/2017

Aprovado em: 27/11/2017

Endereço para correspondência:

prof.mazzardo@gmail.com

Oldemar Mazzardo

Universidade Estadual do Oeste do Paraná

Rua Universitária, 2069

Universitário

85819-110 - Cascavel, PR - Brasil 